\title{
IL-10-producing and naturally occurring CD4+ Tregs: limiting collateral damage
}

\author{
Anne O'Garra, ${ }^{1}$ Pedro L. Vieira, ${ }^{1}$ Paulo Vieira, ${ }^{2}$ and Anne E. Goldfeld ${ }^{3}$
}

\begin{abstract}
1Division of Immunoregulation, The National Institute for Medical Research, London, United Kingdom. 2Unité du Développement des Lymphocytes (CNRS URA 1961), Paris, France. ${ }^{3}$ CBR Institute for Biomedical Research and Department of Medicine, Harvard Medical School, Boston, Massachusetts, USA.
\end{abstract}

\begin{abstract}
Effective immune responses against pathogens are sometimes accompanied by strong inflammatory reactions. To minimize damage to self, the activation of the immune system also triggers anti-inflammatory circuits. Both inflammatory and anti-inflammatory reactions are normal components of the same immune response, which coordinately fight infections while preventing immune pathology. IL-10 is an important suppressive cytokine, produced by a large number of immune cells in addition to the antigen-driven IL-10-producing regulatory and the naturally occurring suppressor $\mathrm{CD}^{+} \mathrm{T}$ cells, which is a key player in anti-inflammatory immune responses. However, additional mechanisms have evolved to ensure that pathogen eradication is achieved with minimum damage to the host. Here we discuss those mechanisms that operate to regulate effector immune responses.
\end{abstract}

IL-10-producing CD4 ${ }^{+}$Tregs (IL-10 Tregs) can be induced in vitro and in vivo under particular conditions of antigenic stimulation (1-8). In mice, these cells share functional properties with naturally occurring $\mathrm{CD} 4{ }^{+} \mathrm{CD} 25^{+}$Tregs (naturally occurring Tregs) $(9-12)$ in that they can inhibit the proliferation of naive $\mathrm{CD}^{+} \mathrm{T}$ cells independently of IL-10 production via cell-cell contact (8). Intriguingly, these IL-10 Tregs can be isolated from TCR-transgenic, recombination-activating gene-deficient (RAG-deficient) mice (6), which are devoid of naturally occurring Tregs and do not express the forkhead-winged helix transcription factor Foxp3 (8), which is required for the development of naturally occurring Tregs (13-16). Thus, IL-10 Tregs and naturally occurring Tregs appear to be developmentally distinct.

IL-10 Tregs inhibit T cell expansion in vivo (2) and in certain murine disease models such as experimental autoimmune encephalomyelitis (EAE) (6) via IL-10-dependent mechanisms. Naturally occurring Tregs also inhibit colitis, via the action of IL-10, which they have been shown to produce in vivo under certain conditions $(13,17,18)$. In humans, IL-10 Tregs limit immune responses to Mycobacterium tuberculosis (MTb) antigens and regulate HIV replication (19), and naturally occurring CD $25^{+}$Tregs have been shown to regulate $\mathrm{T}$ cell responses to HIV-1-specific antigens (20-22). Both Th 1 and Th 2 responses can be regulated by IL-10 Tregs and by naturally occurring Tregs (23). Th 1 cells producing IFN- $\gamma$ are critical for the eradication of intracellular pathogens but are also implicated in inflammatory pathologies $(24,25)$. Th2 cells, on the other hand, which produce IL-4, IL-5, and IL-13, are important for the regulation of immune responses to helminths but also cause allergic pathologies $(24,26)$. In addition to being regulated by naturally occurring Tregs and by IL-10 Tregs, Th1 and Th2 cells also reciprocally regulate the development and function of each other. Because IL-10 is also produced by B lymphocytes $(27,28)$,

Nonstandard abbreviations used: CTLA4, cytotoxic T lymphocyte-associated protein 4; EAE, experimental autoimmune encephalomyelitis; IL-10 Tregs,

IL-10-producing CD4 ${ }^{+}$Tregs; MTb, Mycobacterium tuberculosis; naturally occurring

Tregs, naturally occurring $\mathrm{CD}^{+} \mathrm{CD} 25^{+}$Tregs; NKT cell, NK T cell; RAG,

recombination-activating gene.

Conflict of interest: The authors have declared that no conflict of interest exists.

Citation for this article: J. Clin. Invest. 114:1372-1378 (2004).

doi:10.1172/JCI200423215. by macrophages, by DCs $(29,30)$, and by T cells other than Tregs $(25,27)$, it is clear that multiple cell types may contribute to the regulation of immune responses via their production of this cytokine. Thus regulation of the immune response may occur at various layers, each utilizing different mechanisms that, depending on the degree of inflammation and the host response to infection, are called upon at different stages during immune responses.

\section{Strategic plan for immunoregulation}

Because of the diversity of antigenic specificities expressed by microorganisms and their ability to mutate under immune selective pressure, it is not possible for the immune system to know a priori which antigens will need to be recognized during the course of an infection. Therefore the immune system has evolved mechanisms to generate a large and diverse set of specificities in order to cope with various pathogens. A necessary consequence of this process is that the immune system is also able to recognize, and thus respond to, self antigens (31), which may result in mild or severe autoimmune disorders. A normal immune response, adequately directed against a pathogen, may also cause damage to healthy, nonpathogenic, self through the same inflammatory reactions that are necessary for the efficient eradication of the invading pathogen. This collateral damage sometimes causes more harm to the host than to the pathogen itself because many of the cytokines produced by $\mathrm{T}$ cells, macrophages, and DCs that activate effector responses and eradicate pathogens also mediate inflammatory and autoimmune pathologies (reviewed in refs. 24, 27, and 32).

Several mechanisms that control and regulate the immune system to prevent or minimize damage caused by reactivity to self antigens and over-exuberant immune responses to pathogens have been described. Deletion of autoreactive cells during T and B cell development and the induction of anergy in peripheral self-reactive lymphocytes were proposed as major mechanisms for peripheral tolerance (33). However, avoidance of collateral damage to the host is also achieved by active immune suppression mediated by Treg populations $(9-11,34,35)$.

Various Treg populations have been described, including the $\mathrm{CD}^{+} \mathrm{CD} 25^{+}$subset $(10,12,35,36)$ as well as $\mathrm{CD} 4^{+} \mathrm{CD} 45 \mathrm{RB}^{\text {low }}$ cells $(34,35,37)$, which contain the $\mathrm{CD} 4^{+} \mathrm{CD} 25^{+} \mathrm{T}$ cell population and can in some cases function via the action of IL-10 (17), cytotoxic T 


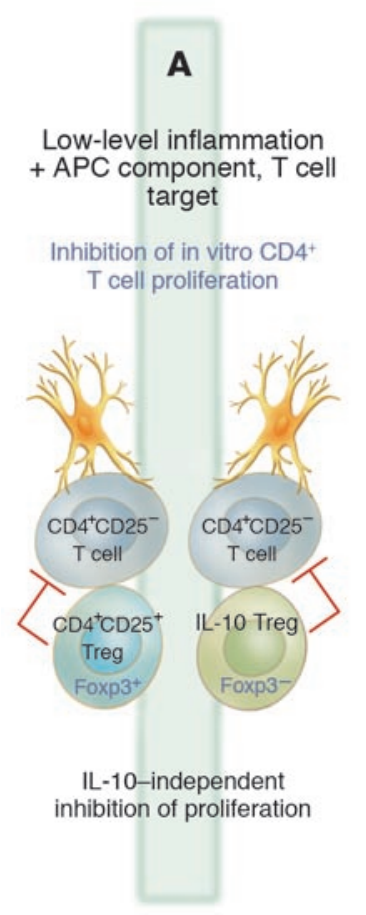

\section{Figure 1}

Layers of regulation of the immune response. At low levels of inflammation (A) both Foxp3 ${ }^{+}$ naturally occurring Tregs and Foxp3- IL-10 Tregs inhibit CD4+ $4^{+}$cell proliferation through IL-10-independent, cell contact-dependent mechanisms. (B) Similar mechanisms may control immune responses to self antigens and autoimmune pathologies associated with low-level inflammation such as gastritis. (C) When strong inflammation occurs, with activation of APCs, effector molecules, such as IL-10 and TGF- $\beta$, secreted by Tregs are required to control CD4+ $\mathrm{T}$ cell responses. TLR, Toll-like receptor. lymphocyte-associated protein 4 (CTLA4) $(37,38)$, and/or TGF- $\beta$ $(35,39-43)$. Other populations of IL-10 $(2-8,19,44)$ and TGF$\beta$-secreting Tregs (45) have also been described. It is unclear at this stage whether or how all of these $T$ cell populations are related with respect to their development and function in the inhibition of the immune response at various levels. $\mathrm{CD} 4^{+}$Tregs are currently a highly active area of research in immunology. We will discuss $\mathrm{CD}^{+}$Tregs in this review as well as other mechanisms of immune regulation that have been described in the last decade. These mechanisms involve Th1- and Th2-derived cytokines, some of which reciprocally regulate these effector populations and, in addition, inhibit APC function. The actions of other cytokines produced by DCs, macrophages, and B cells, which may also regulate immune responses by directing the subsequent adaptive immune response to inhibit immune pathologies, will also be discussed.

\section{Th1 and Th2 cells are on opposing sides}

The nature of the immune response, either Th1 or Th2, determines whether or not adequate pathogen eradication occurs. Th1 cells, by their production of IFN- $\gamma$, are critical for the eradication of intracellular pathogens but can also cause inflammatory pathologies $(24,25)$. Th2 cells, by contrast, are important for the regulation of responses to helminth parasites, but their production of IL-4, IL-5, and IL-13 results in allergic manifestations $(24,26)$. Cytokines directing Th1 and Th 2 responses, and produced by the respective subsets, have been shown to cross-regulate each other's development and function $(26,46,47)$. For example, IL-4 profoundly inhibits the development of Th1 responses via a number of mechanisms, including the downregulation of the IL-12R $\beta 2$ chain (48-50) and the regulatory function of the transcription factor T-bet (51). Conversely, IFN- $\gamma$, which upregulates the IL-12R $\beta 2$ chain (48-50), inhibits the development of Th2 cells (47). That this is important for the regulation of immune responses in vivo has been well established in a mouse model of leishmaniasis. In contrast to most other mouse strains, BALB/c mice infected with Leishmania major respond with a vigorous $\mathrm{Th} 2$ response and are incapable of eradicating the pathogen $(24,52)$. In this system, IL-4 inhibits the development and function of Th1 cells producing IFN- $\gamma$ that are essential for $L$. major clearance $(24,52)$. IL-4 and IL-13 also inhibit the production of proinflammatory cytokines that are involved in pathogen killing by macrophages $(26,46,53)$.

Given that chronic Th1 and Th2 responses are often mutually exclusive, a hypothesis put forward in the mid-1990s proposed that protection from autoimmune diseases, such as EAE and IDDM, could be achieved by shifting from a "Th1" to a "Th2" cytokine milieu that would switch off detrimental Th1-type immune responses (reviewed in ref. 26). It was suggested that administration of soluble antigen without adjuvant or oral administration of soluble antigens $(26,45,46)$ would lead to the inhibition of detrimental Th1 responses via a Th2-dependent or TGF- $\beta$-mediated mechanism. Although Th2 cell-derived cytokines can, under some conditions, protect against autoimmune pathologies by inhibiting Th1 responses (reviewed in refs. 32 and 54), the fact that Th2 cells themselves can also cause immunopathology $(55,56)$ makes it clear that additional mechanisms are needed to regulate both Th1 and Th2 responses, including TGF- $\beta$ (45) and/or IL-10 (27).

\section{Other regulatory circuits}

Regulation of immune responses is a complex process and undoubtedly requires the action of multiple regulators on a variety of effector cells. This is exemplified by the observation that a particular subset of $\mathrm{CD}^{+} \mathrm{T}$ cells, the NK T cell (NKT cell), suppresses antitumor immunity in the mouse through the inhibition of CTL function $(57,58)$. The negative immunoregulatory circuit of CTL-mediated tumour immunity is further mediated by TGF- $\beta$, myeloid cells, IL-13, as well as CD1d-restricted NKT cells. The glycolipid tumor antigen presented by APCs in the context of CD1d is recognized by and activates NKT cells $(57,58)$. 
Activated NKT cells in turn produce IL-13, which acts on $\mathrm{Gr}-1^{+} \mathrm{CD} 11 \mathrm{~b}^{+}$myeloid cells that express the IL-13 receptor. These $\mathrm{Gr}-1^{+} \mathrm{CD} 11 \mathrm{~b}^{+}$myeloid cells then produce TGF- $\beta$ and suppress the $\mathrm{CD}^{+} \mathrm{CTL}$ that kill tumor cells, thereby suppressing tumor immunity $(57,58)$. It is likely that such complex circuits are also in place to regulate immune responses to pathogens, although this still needs to be determined.

\section{IL-10 and a lull in the battle: taking the edge off the immune response}

The regulatory capacity of antigen-driven IL-10 Tregs and of naturally occurring Tregs and the induction of immunosuppressive cytokines such as IL-10 and TGF- $\beta$ provide a new layer of immune regulation to inhibit both Th1- and Th2-type immune responses (Figure 1) (reviewed and referenced in refs. 1-6, 8, 10, 11, 16, 17, 23, $25,27,35,42,44$, and 59-62).

IL-10 is essential in limiting immune responses to numerous pathogens and subsequent immune pathologies $(27,35,63)$. For example, mice carrying a deletion in the IL-10 gene, when infected with the malaria parasite Plasmodium chabaudi chabaudi, mount an overexuberant response that is damaging to the host (64). Furthermore, mice with the same deletion in the IL-10 gene become highly susceptible to inflammatory bowel disease (ref. 65; reviewed in refs. 25,27 , and 63). Although IL-10 was originally described as a cytokine produced by Th2 cells, it is now clear that it is produced by both IL-10 Tregs and other T cells, including Th1 cells $(27,63)$ or, under certain conditions, naturally occurring Tregs and CD8 ${ }^{+}$ T cells (66-68), macrophages, DCs $(29,30)$, and B cells $(27,28)$. Indeed, B cell-derived IL-10 has been shown to inhibit pathology in the autoimmune disease EAE (28). Since IL-10 indirectly inhibits the development of Th1 responses and cytokine production by Th1 cells via inhibition of the production of proinflammatory cytokines such as IL-12 by DCs and macrophages, it is surprising that IL-10 is also produced by Th1 cells $(25,27)$.

\section{Role of IL-10 in infectious diseases and evasion maneuvers of the pathogen}

The role of IL-10 in the regulation of immune responses to infectious diseases has been well documented in experimental mouse models. Injection of recombinant IL-10 or its overexpression in IL-10 transgenic mice enhances survival in mice in toxic shocklike syndromes and leads to inhibition of the immunopathology observed during infection by a wide variety of pathogens (reviewed in ref. 27). Furthermore, IL-10 has been shown to strongly inhibit the immune response to many pathogens including Toxoplasma gondii (69), the malaria parasite P. chabaudi chabaudi (64), Trypanosoma cruzi (70), and Helicobacter hepaticus $(71,72)$. These effects may in part be due to the well-known ability of IL-10 to suppress TNF production (reviewed in ref. 27). Conversely, reduction of IL-10 levels using neutralizing anti-IL-10 or antiIL-10R mAbs, or IL-10 gene-deleted mice, resulted in increased resistance to a variety of pathogens, including Listeria monocytogenes, T. gondii, P. chabaudi chabaudi, Candida albicans and T. cruzi, but in some cases resulted in immunopathology (reviewed in ref. 27). Again, these effects are due perhaps to TNF-dependent mechanisms as well as an IL-12-induced Th1 response. Taken together, these results indicate that IL-10 can block certain immunopathologies while its loss can result in better protection from some pathogen infections, probably through the enhancement of Th1 responses as well as the production of TNF.
The role of IL-10 in blunting immune responses to specific antigens was demonstrated in a series of experiments using human PBMCs from individuals with documented infection by a variety of pathogens. Immune responsiveness was improved in the presence of anti-IL-10 mAbs in leishmaniasis (73), filariasis (74), schistosomiasis (75), leprosy $(76)$, and tuberculosis $(19,77)$.

The relative levels of IL-10 and IFN- $\gamma$ produced by $T$ cells are thus an important determinant of the balance between clearance and persistent infection with certain pathogens such as $M T b(19,63,78-80)$, Mycobacterium avium (81), L. major (82-84), L. monocytogenes (85) and T. gondii (69). Like TNF, IFN- $\gamma$ is reciprocally regulated by IL-10 (27) and is critical in the clearance of $M T b(86,87)$. Notably, several studies have also demonstrated that both TNF and IFN- $\gamma$ can be detrimental in tuberculosis patients $(88,89)$, particularly in the central nervous system (90). Therefore the ratio of IL-10 to either TNF or IFN- $\gamma$ appears to be critical to the ability of the immune system to eradicate $M T b$ with minimum pathology.

It is of note that of the estimated 42 million individuals infected with HIV-1 globally, over 11 million are coinfected with MTb (91). Recent studies demonstrated that the relative levels of IL-10 and TNF elicited in $M T b$ recall responses that have a direct impact on HIV-1 replication levels (80). TNF, which is critical in controlling $M T b$ infection, enhances HIV replication. Conversely, IL-10 and the presence of IL-10 Tregs, which blunt immune responses to MTb antigens, inhibited HIV-1 replication in an ex vivo experimental model, in part via their inhibition of TNF production (80). On the other hand, recent work demonstrated that $\mathrm{CD} 25^{+} \mathrm{CD} 4^{+}$Tregs from PBMCs of asymptomatic HIV-infected individuals regulate HIV-1 specific immune responses in a cell-contact dependent, IL-10-independent, manner (21). Another study has shown that induction of Tregs by cytomegalovirus also inhibits anti-HIV-1 immune responses (20).

\section{Are IL-10 and naturally occurring Tregs allies?}

The $T$ cell source of IL-10 during responses to infectious pathogens could be Th 1 cells, Th 2 cells, CD8 ${ }^{+} \mathrm{T}$ cells (reviewed in refs. 25, 27, 63, and 68$)$, or Tregs $(1-8,19,83,92)$. Thus, although naturally occurring and IL-10 Tregs were originally implicated in the regulation of autoimmune and/or inflammatory pathologies $(25,35)$, they also modulate responses to infectious pathogens. IL-10 Tregs were shown to inhibit $\mathrm{T}$ cell responses to $M T b$ antigens in vitro in the human host $(19,79)$. Subsequently, it has been suggested that in $H$. hepaticus infections in mice, antigen-driven IL-10 Tregs are critical in regulating colitis induced by this organism (93). On the other hand, it was shown in L. major infections in mice that naturally occurring CD25+ Tregs regulate the immune response to the pathogen and under these conditions produce IL-10 (83).

Naturally occurring Tregs have been shown to inhibit immune pathologies and autoimmune diseases in vivo, probably through their ability to control $\mathrm{T}$ cell numbers in vivo and their manipulation of the cytokine milieu as described above $(16,35)$. They also regulate naive $\mathrm{T}$ cell proliferation in vitro. Furthermore, the specific mechanisms used by naturally occurring Tregs for their suppressive function is influenced by the specific immune reaction they are involved in regulating. This can involve cell-contact-dependent mechanisms with an as-yet-unidentified molecular basis, CTLA4, and cytokines, including IL-10 and TGF- $\beta$ (10, $12,16,17,35,37,38,40-43,94)$ or, as more recently described, indoleamine 2,3-dioxygenase (IDO) $(95,96)$. Some mechanisms whereby naturally occurring Tregs may inhibit reactivities to self, 


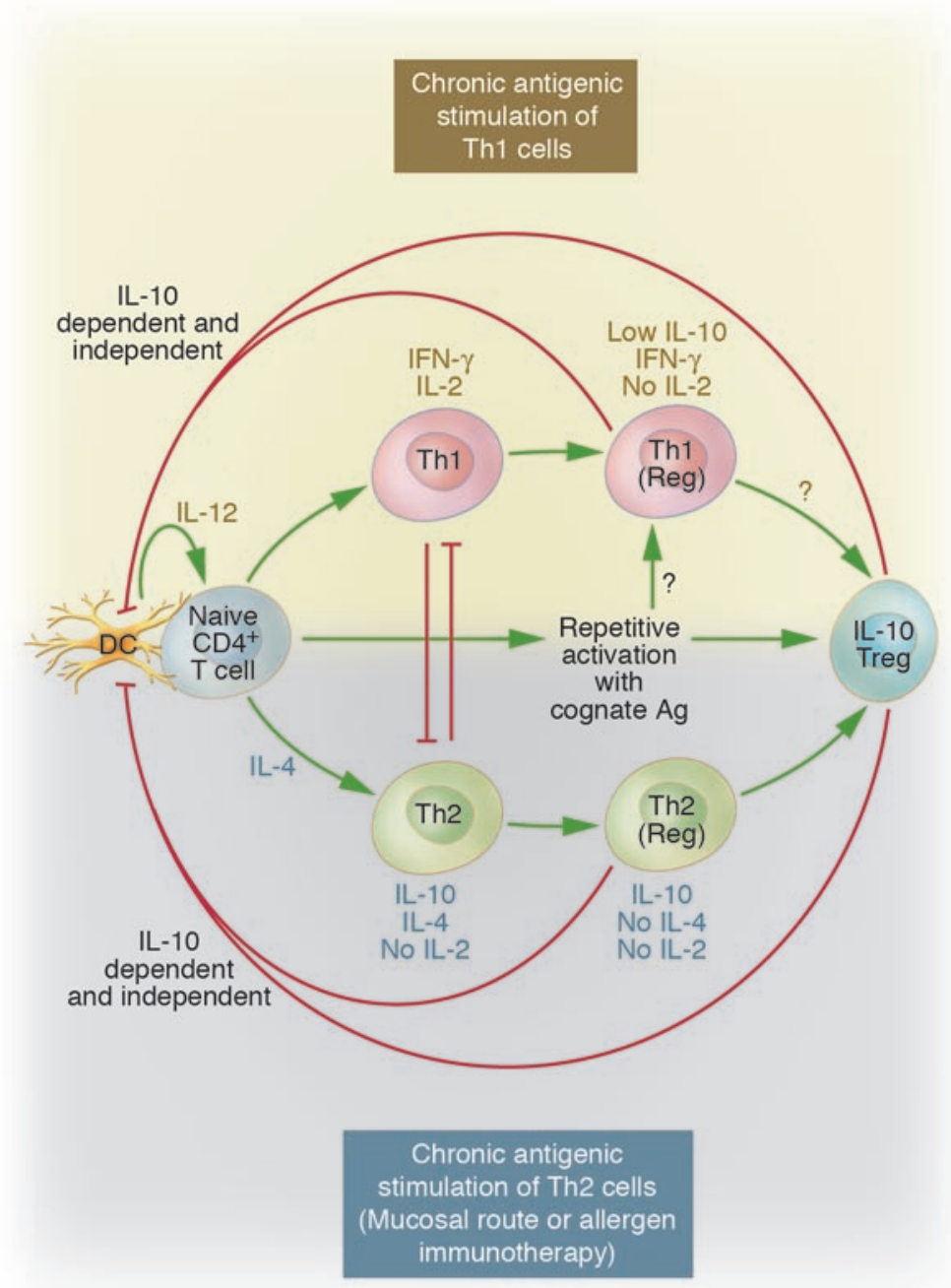

\section{Figure 2}

Cross-regulation of effector Th responses and feedback inhibition of naive T cell proliferation. IL-12 produced by the dendritic cell drives Th1 cells (IFN- $\gamma$ ). IL-4 produced by a variety of sources, including in some cases the naive $T$ cell itself, drives Th2 cells to secrete cytokines (IL-4/IL-10). These effector subsets and the cytokines they produce or that drive them inhibit each other's differentiation. Repetitive activation of effector Th cells with cognate antigen results in the differentiation of regulatory Th cells with inhibitory function via as-yet-unknown mechanisms. Proliferation of naive $\mathrm{CD} 4^{+} \mathrm{T}$ cells is controlled by inhibition of the antigen-presenting cell function of the DCs via both IL-10-dependent and IL-10-independent mechanisms. Green lines with arrows, activation/differentiation; red lines with block, inhibition. either in autoimmunity or inflammatory pathologies that may be associated with microorganisms, such as is found to occur in colitis $(17,35)$, and appear to also be used to regulate immune responses to pathogens $(19,83,93)$. This is undoubtedly essential in order to limit an immune response to a pathogen and thus avoid immunopathology in the host. The ability to control the number of lymphocytes $(16,35,97)$ and the class and magnitude of the immune response $(24,27,63,98)$ could confer an evolutionary advantage whereby a host could effectively fight an infection while limiting secondary immunopathology. Alternatively, pathogen-induced immunosuppression provides a powerful immunoevasion strategy for the invading organism.

IL-10 Tregs can be induced under particular experimental conditions of antigenic stimulation in vitro and in vivo $(1-8,99)$ and in natural infection in vivo (reviewed in refs. 19, 25, 27, 71, 72, 83, and 92). In addition, IL-10 is also induced in vivo by administration of soluble protein antigen, which is known to generate anergy/tolerance $(2,5,7,8,99)$. Sundstedt et al. have demonstrated that IL-10 Tregs can be induced by repeated intranasal administration of an antigenic peptide of myelin basic protein and that these regulatory cells inhibit the proliferation of naive myelin basic protein-specific $\mathrm{T}$ cells both in vitro and in vivo. However, in keeping with previous findings using $\mathrm{CD} 4^{+} \mathrm{CD} 25^{+}$Tregs $(12,97)$, it was discovered that IL-10 mediated the suppression of naive T cells in vivo but not in vitro $(2,8)$. In support of these findings, it was reported that naive $\mathrm{CD}^{+} \mathrm{T}$ cells generated in vitro as a homogeneous population of IL-10-secreting cells, possibly representative of those in vivoderived populations described earlier, show regulatory function that blocks EAE. In addition, the development and function of these cells in vivo is IL-10 dependent (6). However, the inhibition of in vitro $\mathrm{T}$ cell proliferation by these IL-10 Tregs is not IL-10dependent $(2,8)$. It is thus possible that naturally occurring and antigen-driven IL-10 Tregs use different mechanisms when they regulate $\mathrm{T}$ cell proliferation in vitro or in vivo or when they control different in vivo immune responses and/or pathologies observed in colitis and gastritis (94).

In mice, IL-10 Tregs share some functional properties with naturally occurring $\mathrm{CD} 4{ }^{+} \mathrm{CD} 25^{+}$Tregs. These naturally occurring Tregs were first identified by their ability to control various manifestations of autoimmunity secondary to neonatal thymectomy in mice (10) and have been shown to inhibit a number of autoimmune pathologies $(10,12,35)$. More recently, they were shown to inhibit the proliferation of naive $\mathrm{CD} 4^{+} \mathrm{T}$ cells via a cell-cell contact-dependent mechanism in both mouse and human $(12,100)$. It was also shown that this property is shared with IL-10 Tregs $(2,8)$. This suppression of naive $\mathrm{T}$ cell proliferation was suggested in some systems to be mediated by cell-surface-bound TGF- $\beta$ (41). 
The development of $\mathrm{CD} 4^{+} \mathrm{CD} 25^{+}$naturally occurring Tregs has been shown to be dependent on Foxp3 (refs. 13-15; reviewed in ref. 16). The absence of functional Foxp3 in the natural mutant scurfy mouse and in the Foxp3 $3^{-/-}$mouse results in a severe lymphoproliferative disorder and inflammatory pathologies, which are also similar to those observed in patients carrying a Foxp3 mutation (refs. 13 and 15; reviewed in ref. 16). Furthermore, transduction of nonregulatory $\mathrm{T}$ cells with Foxp3 in a retrovirus or as a transgene conferred regulatory functions upon these cells both in vitro and in vivo (13-15). IL-10 Tregs can be isolated from TCR-transgenic mice on a RAG-deficient background that do not possess any naturally occurring $\mathrm{CD} 4{ }^{+} \mathrm{CD} 25^{+}$Tregs (6). Furthermore, IL-10 Tregs express low to undetectable levels of Foxp3 in contrast to the naturally occurring Tregs, yet both types of Tregs inhibit naive $T$ cell proliferation independently of IL-10 via a cell contact-dependent mechanism $(8,12,100)$. Thus, IL-10 Tregs and naturally occurring Tregs appear to be developmentally distinct, and Foxp3 is not required for the inhibition of naive $\mathrm{T}$ cell proliferation in this system. Whereas in vivo inhibition of the expansion of T cell numbers $(2,97)$, EAE $(2,6)$, and colitis $(17)$ by either $\mathrm{CD} 4^{+} \mathrm{CD} 25^{+}$Tregs and IL-10 Tregs has been shown to be mediated via IL-10-dependent mechanisms, other pathologies are not $(12,94)$.

In addition to the inhibition of Th1 responses by IL-10 via its inhibitory action on DCs and macrophages, naturally occurring $\mathrm{CD}^{+} \mathrm{CD} 25^{+}$Tregs can also inhibit the development of Th1 and Th2 responses (18). In the human, IL-10 produced by Tregs obtained from immunocompetent tuberculosis patients who displayed no $\mathrm{T}$ cell-mediated skin reactivity to subcutaneous injection of purified protein derivative injection inhibited the proliferation of alloreactive T cells and their production of IFN- $\gamma$ and TNF in vitro $(19,79,80)$. In this case IL-10 may operate via inhibition of IL-10-sensitive APCs, such as DCs and macrophages, which may have been activated in the context of the innate immune response and/or via a direct effect on the T cell. Whether these IL-10 Tregs induced in chronic infectious disease developed in the thymus via a Foxp3-dependent mechanism or in the periphery by repeated antigenic stimulation as do the antigen-driven IL-10 Tregs in mouse models discussed earlier (2, 6, 8) remains to be determined, although the latter possibility seems probable. On this note, it has been reported that mouse $\mathrm{CD} 4^{+} \mathrm{CD} 25^{+}$ Tregs produce IL-10 and regulate the immune response to L. major, in part via the action of IL-10 (83), but again, since CD25 is expressed on activated $\mathrm{CD}^{+} \mathrm{T}$ cells in this system, the relationship of these cells to naturally occurring $\mathrm{CD} 4^{+} \mathrm{CD} 25^{+}$Tregs or peripherally-derived IL-10 Tregs is unclear. This is also the case for antigen-driven IL-10 T cells arising during $H$. hepaticus infection, which inhibit the development of colitis via the action of IL-10 (93).

Although blockade of IL-10 has been suggested as a strategy for immunotherapy in chronic infectious disease, since this leads to sterilizing immunity $(83,84)$, this has also been shown in some systems to result in a loss of immunity to reinfection (83). Thus a balance between effector $\mathrm{T}$ cells and Tregs in sites of chronic infection may allow parasite survival in the host while maintaining host immune memory and control of the pathogen.
It is important to bear in mind that IL-4 also plays a major role in regulating the immune response to L. major in BALB/c mice via inhibition of the development and function of Th1 cells (24, 52). Interestingly, it has also been reported that $\mathrm{CD} 4{ }^{+} \mathrm{CD} 45 \mathrm{RB}{ }^{\text {low }}$ cells, which contain $\mathrm{CD} 4^{+} \mathrm{CD} 25^{+}$Tregs and possibly some effector populations, were shown to inhibit colitis via the action of TGF- $\beta$ and IL-10 but not IL-4 $(17,40)$ whereas the same population of T cells inhibited the immune response to $L$. major via the action of IL-4 (34). Thus, the coexistence of Th2 cells and IL-10 and naturally occurring Tregs is worth considering although it is clear that under some conditions both types of Tregs and IL-10 can inhibit allergy-inducing Th2 responses $(44,60)$.

\section{An alliance against immunopathology}

Activation of DCs happens mostly through engagement of Tolllike and other pattern-recognition receptors (101). The type of DCs presenting the antigen and the conditions under which the response is initiated determine the class of immune response elicited and its outcome (102). B lymphocytes, for example, produce cytokines such as IL-10 and TNF, which can modulate the type and the magnitude of the immune response against a given antigen and inhibit or drive autoimmunity $(27,28,103,104)$. Thus it is apparent that many cells may contribute to the regulation of immune responses via their production of IL-10 rather than proinflammatory cytokines and, in addition, that different regulatory mechanisms will be involved during immune responses at different stages, depending on the degree of inflammation, the specific pathogen, and the stage of the immune response.

\section{Limiting collateral damage: final speculation}

Mice or humans with a defect in the transcription factor Foxp3 display a strong lymphoproliferative disorder and extreme immune dysregulation at the neonatal stage (reviewed in ref. 16). Some of these manifestations are reminiscent of the phenotype observed in $\mathrm{CTLA4^{-/- }}$ mice, which again show a strong lymphoproliferative disorder at an early age in ontogeny leading to immune pathologies (105). By contrast $I L-10^{-/-}$mice do not exhibit this lymphoproliferative disorder but only later in life become susceptible to colitis, dependent upon the gut flora $(35,65)$, consistent with the notion that IL-10 plays a crucial role in the regulation of immune responses at the interface of innate and adaptive immunity (99). This would explain the fundamental role of IL-10 Tregs and other IL-10 producing cells in the regulation of immune responses to infectious pathogens, in which one of their most important roles is likely to be the feedback inhibition to limit immune responses and minimize inflammatory pathologies (Figure 2). Neutralization of IL-10 during infections may prove to be a valuable therapeutic tool to enhance immune responses in chronic infection.

Address correspondence to: Anne O'Garra, The National Institute for Medical Research, Division of Immunoregulation, The Ridgeway, Mill Hill, London, NW7 1AA, United Kingdom. Phone: 44-208816-2508; Fax: 44-208-816-2564; E-mail: aogarra@nimr.mrc.ac.uk.

\footnotetext{
1. Sundstedt, A., et al. 1997. Immunoregulatory role of IL-10 during superantigen-induced hyporesponsiveness in vivo. J. Immunol. 158:180-186.

2. Sundstedt, A., O'Neill, E.J., Nicolson, K.S., and Wraith, D.C. 2003. Role for IL-10 in suppression mediated by peptide-induced regulatory $\mathrm{T}$ cells in vivo. J. Immunol. 170:1240-1248.

3. Groux, H., et al. 1997. A CD4+ T-cell subset inhibits
}

antigen-specific T-cell responses and prevents colitis. Nature. 389:737-742.

4. Roncarolo, M.G., Bacchetta, R., Bordignon, C., Narula, S., and Levings, M.K. 2001. Type 1 T regulatory cells. Immunol. Rev. 182:68-79.

5. Buer, J., et al. 1998. Interleukin 10 secretion and impaired effector function of major histocompatibility complex class II-restricted $\mathrm{T}$ cells anergized in vivo. J. Exp. Med. 187:177-183.

6. Barrat, F.J., et al. 2002. In vitro generation of interleukin 10-producing regulatory $\mathrm{CD} 4(+) \mathrm{T}$ cells is induced by immunosuppressive drugs and inhibited by $\mathrm{T}$ helper type 1 (Th1)- and Th2-inducing cytokines. J. Exp. Med. 195:603-616.

7. Pontoux, C., Banz, A., and Papiernik, M. 2002. Natural CD4 CD25(+) regulatory T cells control the burst 
of superantigen-induced cytokine production: the role of IL-10. Int. Immunol. 14:233-239.

8. Vieira, P.L., et al. 2004. IL-10 secreting regulatory T cells do not express Foxp3 but have comparable regulatory function to naturally occuring CD4+CD25+ regulatory T cells. J. Immunol. 172:5986-5993.

9. Sakaguchi, S., Sakaguchi, N., Asano, M., Itoh, M., and Toda, M. 1995. Immunologic self-tolerance maintained by activated $\mathrm{T}$ cells expressing IL-2 receptor alpha-chains (CD25). Breakdown of a single mechanism of self-tolerance causes various autoimmune diseases. J. Immunol. 155:1151-1164.

10. Sakaguchi, S., et al. 2001. Immunologic tolerance maintained by CD25+ CD4+ regulatory T cells: their common role in controlling autoimmunity, tumor immunity, and transplantation tolerance. Immunol. Rev. 182:18-32.

11. Shevach, E.M. 2000. Suppressor T cells: Rebirth, function and homeostasis. Curr. Biol. 10:R572-R575.

12. Shevach, E.M. 2002. CD4+ CD25+ suppressor T cells: more questions than answers. Nat. Rev. Immunol. 2:389-400.

13. Fontenot, J.D., Gavin, M.A., and Rudensky, A.Y 2003. Foxp3 programs the development and function of CD $4+\mathrm{CD} 25+$ regulatory T cells. Nat. Immunol. 4:330-336.

14. Hori, S., Nomura, T., and Sakaguchi, S. 2003. Control of regulatory $\mathrm{T}$ cell development by the transcription factor Foxp3. Science. 299:1057-1061.

15. Khattri, R., Cox, T., Yasayko, S.A., and Ramsdell, F. 2003. An essential role for Scurfin in CD4+CD25+ T regulatory cells. Nat. Immunol. 4:337-342.

16. Ramsdell, F. 2003. Foxp3 and natural regulatory T cells: key to a cell lineage? Immunity. 19:165-168.

17. Asseman, C., Mauze, S., Leach, M.W., Coffman, R.L., and Powrie, F. 1999. An essential role for interleukin 10 in the function of regulatory $\mathrm{T}$ cells that inhibit intestinal inflammation. J. Exp. Med. 190:995-1004.

18. Liu, H., Hu, B., Xu, D., and Liew, F.Y. 2003. $\mathrm{CD} 4+\mathrm{CD} 25+$ regulatory $\mathrm{T}$ cells cure murine colitis: the role of IL-10, TGF-beta, and CTLA4. J. Immunol. 171:5012-5017.

19. Boussiotis, V.A., et al. 2000. IL-10-producing T cells suppress immune responses in anergic tuberculosis patients. J. Clin. Invest. 105:1317-1325.

20. Aandahl, E.M., Michaelsson, J., Moretto, W.J., Hecht, F.M., and Nixon, D.F. 2004. Human CD4+ CD25+ regulatory $\mathrm{T}$ cells control $\mathrm{T}$-cell responses to human immunodeficiency virus and cytomegalovirus antigens. J. Virol. 78:2454-2459.

21. Kinter, A.L., et al. 2004. CD25+CD4+ regulatory T cells from the peripheral blood of asymptomatic $\mathrm{HIV}$-infected individuals regulate CD4 and CD8 HIV-specific $\mathrm{T}$ cell immune responses in vitro and are associated with favorable clinical markers of disease status. J. Exp. Med. 200:331-343.

22. Oswald-Richter, K., et al. 2004. HIV infection of naturally occurring and genetically reprogrammed human regulatory T-cells. PLoS Biol. 2:E198.

23. Xu, D., et al. 2003. CD4+CD25+ regulatory T cells suppress differentiation and functions of Th1 and Th2 cells, Leishmania major infection, and colitis in mice. J. Immunol. 170:394-399.

24. Sher, A., and Coffman, R.L. 1992. Regulation of immunity to parasites by $\mathrm{T}$ cells and $\mathrm{T}$ cell-derived cytokines. Annu. Rev. Immunol. 10:385-409.

25. O'Garra, A., and Robinson, D. 2004. Development and function of $\mathrm{T}$ helper 1 cells. Adv. Immunol. 83:133-162.

26. O'Garra, A. 1998. Cytokines induce the development of functionally heterogeneous $\mathrm{T}$ helper cell subsets. Immunity. 8:275-283.

27. Moore, K.W., de Waal Malefyt, R., Coffman, R.L., and O'Garra, A. 2001. Interleukin-10 and the interleukin10 receptor. Annu. Rev. Immunol. 19:683-765.

28. Fillatreau, S., Sweenie, C.H., McGeachy, M.J., Gray, D., and Anderton, S.M. 2002. B cells regulate autoimmunity by provision of IL-10. Nat. Immunol. 3:944-950.
29. McGuirk, P., McCann, C., and Mills, K.H. 2002. Pathogen-specific T regulatory 1 cells induced in the respiratory tract by a bacterial molecule that stimulates interleukin 10 production by dendritic cells: a novel strategy for evasion of protective $T$ helper type 1 responses by Bordetella pertussis. J. Exp. Med. 195:221-231.

30. Edwards, A.D., et al. 2002. Microbial recognition via Toll-like receptor-dependent and -independent pathways determines the cytokine response of murine dendritic cell subsets to CD40 triggering. J. Immunol. 169:3652-3660.

31. Ohno, S., Epplen, J.T., Matsunaga, T., and Hozumi, T. 1981. The curse of Prometheus is laid upon the immune system. Prog. Allergy. 28:8-39.

32. O'Garra, A., Steinman, L., and Gijbels, K. 1997. CD4+ T-cell subsets in autoimmunity. Curr. Opin. Immunol. 9:872-883.

33. Jenkins, M.K., et al. 1991. Induction and maintenance of anergy in mature T cells. Adv. Exp. Med. Biol. 292:167-176

34. Powrie, F., Correa-Oliveira, R., Mauze, S., and Coffman, R.L. 1994. Regulatory interactions between CD45RBhigh and CD45RBlow CD4+ T cells are important for the balance between protective and pathogenic cell-mediated immunity. J. Exp. Med. 179:589-600.

35. Maloy, K.J., and Powrie, F. 2001. Regulatory T cells in the control of immune pathology. Nat. Immunol. 2:816-822.

36. Cobbold, S.P., Graca, L., Lin, C.Y., Adams, E., and Waldmann, H. 2003. Regulatory T cells in the induction and maintenance of peripheral transplantation tolerance. Transpl. Int. 16:66-75.

37. Read, S., Malmstrom, V., and Powrie, F. 2000. Cytotoxic $\mathrm{T}$ lymphocyte-associated antigen 4 plays an essential role in the function of $\mathrm{CD} 25(+) \mathrm{CD} 4(+)$ regulatory cells that control intestinal inflammation. J. Exp. Med. 192:295-302.

38. Takahashi, T., et al. 2000. Immunologic self-tolerance maintained by $\mathrm{CD} 25(+) \mathrm{CD} 4(+)$ regulatory $\mathrm{T}$ cells constitutively expressing cytotoxic T lymphocyte-associated antigen 4. J. Exp. Med. 192:303-310

39. Seddon, B., and Mason, D. 1999. Regulatory T cells in the control of autoimmunity: the essential role of transforming growth factor $\mathrm{b}$ and interleukin 4 in the prevention of autoimmune thryroiditis in rats by peripheral CD4+ CD45RC- cells and CD4+ CD8thymocytes. J. Exp. Med. 189:279-288.

40. Powrie, F., Carlino, J., Leach, M.W., Mauze, S., and Coffman, R.L. 1996. A critical role for transforming growth factor-beta but not interleukin 4 in the suppression of $\mathrm{T}$ helper type 1-mediated colitis by CD45RB(low) CD4+ T cells. J. Exp. Med. 183:2669-2674.

41. Nakamura, K., Kitani, A., and Strober, W. 2001. Cell contact-dependent immunosuppression by $\mathrm{CD} 4(+) \mathrm{CD} 25(+)$ regulatory $\mathrm{T}$ cells is mediated by cell surface-bound transforming growth factor beta. J. Exp. Med. 194:629-644.

42. Green, E.A., Gorelik, L., McGregor, C.M., Tran, E.H., and Flavell, R.A. 2003. CD4+CD25+ T regulatory cells control anti-islet CD8+ T cells through TGFbeta-TGF-beta receptor interactions in type 1 diabetes. Proc. Natl. Acad. Sci. U. S. A. 100:10878-10883.

43. Oida, T., et al. 2003. CD4+CD25- T cells that express latency-associated peptide on the surface suppress CD4+CD45RBhigh-induced colitis by a TGF-betadependent mechanism. J. Immunol. 170:2516-2522.

44. Akbari, O., et al. 2002. Antigen-specific regulatory T cells develop via the ICOS-ICOS-ligand pathway and inhibit allergen-induced airway hyperreactivity. Nat. Med. 8:1024-1032.

45. Weiner, H.L. 1997. Oral tolerance: immune mechanisms and treatment of autoimmune diseases. Immunol. Today. 18:335-343.

46. Abbas, A.K., Murphy, K.M., and Sher, A. 1996. Func- tional diversity of helper T lymphocytes. Nature. 383:787-793.

47. Fitch, F.W., McKisic, M.D., Lancki, D.W., and Gajewski, T.F. 1993. Differential regulation of murine T lymphocyte subsets. Annu. Rev. Immunol. 11:29-48.

48. Szabo, S., Dighe, A.S., Gubler, U., and Murphy, K.M. 1997. Regulation of the interleukin (IL)- $12 \beta 2$ subunit expression in developing T helper 1 (Th1) and Th2 cells. J. Exp. Med. 185:817-824.

49. Rogge, L., et al. 1997. Selective expression of an interleukin-12 receptor component by human $\mathrm{T}$ helper 1 cells. J. Exp. Med. 185:825-831.

50. Murphy, K.M., et al. 2000. Signaling and transcription in T helper development. Annu. Rev. Immunol. 18:451-494.

51. Szabo, S.J., et al. 2000. A novel transcription factor, T-bet, directs Th1 lineage commitment. Cell. 100:655-669.

52. Locksley, R.M., and Scott, P. 1991. Helper T-cell subsets in mouse leishmaniasis:induction, expansion and effector function. Immunol. Today. 12:58-61.

53. Paul, W.E., and Seder, R.A. 1994. Lymphocyte responses and cytokines. Cell. 76:241-251.

54. Powrie, F., and Coffman, R.L. 1993. Cytokine regulation of T-cell function: potential for therapeutic intervention. Immunol. Today. 14:270-274.

55. Lafaille, J.J., et al. 1997. Myelin basic protein-specific $\mathrm{T}$ helper 2 (Th2) cells cause experimental autoimmune encephalomyelitis in immunodeficient hosts rather than protect them from disease. J. Exp. Med. 186:307-312.

56. Pakala, S.V., Kurrer, M.O., and Katz, J.D. 1997. T helper 2 (Th2) cells induce acute pancreatitis amd diabetes in immune-compromised non-obese diabetic (NOD) mice. J. Exp. Med. 186:299-306.

57. Terabe, M., et al. 2003. Transforming growth factor-beta production and myeloid cells are an effector mechanism through which CD1d-restricted T cells block cytotoxic T lymphocyte-mediated tumor immunosurveillance: abrogation prevents tumor recurrence. J. Exp. Med. 198:1741-1752.

58. Terabe, M., Park, J.M., and Berzofsky, J.A. 2004. Role of IL-13 in regulation of anti-tumor immunity and tumor growth. Cancer Immunol. Immunother. 53:79-85.

59. Blaser, K., and Akdis, C.A. 2004. Interleukin-10, T regulatory cells and specific allergy treatment. Clin. Exp. Allergy. 34:328-331.

60. Akdis, C.A., and Blaser, K. 2001. Role of IL-10 in allergen-specific immunotherapy and normal response to allergens. Microbes Infect. 3:891-898.

61. O'Garra, A., and Vieira, P. 2004. Regulatory T cells and mechanisms of immune system control. Nat. Med. 10:801-805.

62. O'Garra, A., and Vieira, P. 2003. Twenty-first century Foxp3. Nat. Immunol. 4:304-306.

63. Trinchieri, G. 2001. Regulatory role of T cells producing both interferon gamma and interleukin 10 in persistent infection. J. Exp. Med. 194:F53-F57.

64. Li, C., Corraliza, I., and Langhorne, J. 1999. A defect in interleukin-10 leads to enhanced malarial disease in Plasmodium chabaudi chabaudi infection in mice. Infect. Immun. 67:4435-4442.

65. Kuhn, R., Lohler, J., Rennick, D., Rajewsky, K., and Muller, W. 1993. Interleukin-10 deficient mice develop chronic enterocolitis. Cell. 75:263-274.

66. Tanchot, C., et al. 1998. Modifications of CD8+ T cell function during in vivo memory or tolerance induction. Immunity. 8:581-590.

67. Gilliet, M., and Liu, Y.J. 2002. Generation of human CD8 $\mathrm{T}$ regulatory cells by CD40 ligandactivated plasmacytoid dendritic cells. J. Exp. Med. 195:695-704.

68. Salgame, P., et al. 1991. Differing lymphokine profiles of functional subsets of human CD4 and CD8 T cell clones. Science. 254:279-282.

69. Gazzinelli, R.T., Oswald, I.P., James, S.L., and Sher, A. 1992. IL-10 inhibits parasite killing and nitrogen 
oxide production by IFN-gamma-activated macrophages. J. Immunol. 148:1792-1796.

70. Hunter, C.A., et al. 1997. IL-10 is required to prevent immune hyperactivity during infection with Trypanosoma cruzi. J. Immunol. 158:3311-3316.

71. Kullberg, M.C., et al. 1998. Helicobacter hepaticus triggers colitis in specific-pathogen-free interleukin10 (IL-10)-deficient mice through an IL-12- and gamma interferon-dependent mechanism. Infect. Immun. 66:5157-5166.

72. Maloy, K.J., et al. 2003. CD4+CD25+ T(R) cells suppress innate immune pathology through cytokinedependent mechanisms. J. Exp. Med. 197:111-119.

73. Carvalho, E.M., Barral, A., Costa, J.M., Bittencourt, A., and Marsden, P. 1994. Clinical and immunopathological aspects of disseminated cutaneous leishmaniasis. Acta Trop. 56:315-325

74. Mahanty, S., et al. 1997. Regulation of parasite antigen-driven immune responses by interleukin-10 (IL-10) and IL-12 in lymphatic filariasis. Infect. Immun. 65:1742-1747.

75. King, C.L., et al. 1996. Cytokine control of parasitespecific anergy in human urinary schistosomiasis. IL-10 modulates lymphocyte reactivity. J. Immunol. 156:4715-4721.

76. Sieling, P.A., et al. 1993. Immunosuppressive roles for IL-10 and IL-4 in human infection. In vitro modulation of $\mathrm{T}$ cell responses in leprosy. J. Immunol. 150:5501-5510

77. Gong, J.H., et al. 1996. Interleukin-10 downregulates Mycobacterium tuberculosis-induced Th1 responses and CTLA-4 expression. Infect. Immun. 64:913-918.

78. Gerosa, F., et al. 1999. CD4(+) T cell clones producing both interferon-gamma and interleukin-10 predominate in bronchoalveolar lavages of active pulmonary tuberculosis patients. Clin. Immunol. 92:224-234

79. Delgado, J.C., et al. 2002. Antigen-specific and persistent tuberculin anergy in a cohort of pulmonary tuberculosis patients from rural Cambodia. Proc. Natl. Acad. Sci. U. S. A. 99:7576-7581.

80. Ranjbar, S., Ly, N., Thim, S., Reynes, J.M., and Goldfeld, A.E. 2004. Mycobacterium tuberculosis recall antigens suppress HIV-1 replication in anergic donor cells via CD8 $+\mathrm{T}$ cell expansion and increased IL-10 levels. J. Immunol. 172:1953-1959.
81. Silva, R.A., Pais, T.F., and Appelberg, R. 2001. Blocking the receptor for IL-10 improves antimycobacterial chemotherapy and vaccination. J. Immunol. 167:1535-1541.

82. Kane, M.M., and Mosser, D.M. 2001. The role of IL-10 in promoting disease progression in leishmaniasis. J. Immunol. 166:1141-1147.

83. Belkaid, Y., Piccirillo, C.A., Mendez, S., Shevach, E.M., and Sacks, D.L. 2002. CD4+CD25+ regulatory T cells control Leishmania major persistence and immunity. Nature. 420:502-507.

84. Murray, H.W., et al. 2002. Interleukin-10 (IL-10) in experimental visceral leishmaniasis and IL-10 receptor blockade as immunotherapy. Infect. Immun. 70:6284-6293.

85. Tripp, C.S., Kanagawa, O., and Unanue, E.R. 1995. Secondary response to Listeria infection requires IFN-gamma but is partially independent of IL-12 J. Immunol. 155:3427-3432.

86. Keane, J., et al. 2001. Tuberculosis associated with infliximab, a tumor necrosis factor alpha-neutralizing agent. N. Engl. J. Med. 345:1098-1104.

87. Flynn, J.L., and Chan, J. 2001. Immunology of tuberculosis. Annu. Rev. Immunol. 19:93-129.

88. Smith, S., et al. 2002. Local role for tumor necrosis factor alpha in the pulmonary inflammatory response to Mycobacterium tuberculosis infection. Infect. Immun. 70:2082-2089.

89. Fenhalls, G., et al. 2002. In situ detection of Mycobacterium tuberculosis transcripts in human lung granulomas reveals differential gene expression in necrotic lesions. Infect. Immun. 70:6330-6338.

90. Tsenova, L., Bergtold, A., Freedman, V.H., Young, R.A., and Kaplan, G. 1999. Tumor necrosis factor alpha is a determinant of pathogenesis and disease progression in mycobacterial infection in the central nervous system. Proc. Natl. Acad. Sci. U. S. A. 96:5657-5662.

91. 2002. Joint United Nations Programme on HIV/ AIDS (UNAIDS). Report on the global HIV/AIDS epidemic 2002. UNAIDS/02.26E. http://www. unaids.org.

92. Belkaid, Y., et al. 2001. The role of interleukin (IL)-10 in the persistence of Leishmania major in the skin after healing and the therapeutic potential of antiIL-10 receptor antibody for sterile cure. J. Exp. Med.
194:1497-1506.

93. Kullberg, M.C., et al. 2002. Bacteria-triggered CD4(+) $\mathrm{T}$ regulatory cells suppress Helicobacter hepaticusinduced colitis. J. Exp. Med. 196:505-515.

94. Suri-Payer, E., and Cantor, H. 2001. Differential cytokine requirements for regulation of autoimmune gastritis and colitis by CD4(+)CD25(+) T cells. J. Autoimmun. 16:115-123.

95. Grohmann, U., Fallarino, F., and Puccetti, P. 2003. Tolerance, DCs and tryptophan: much ado about IDO. Trends Immunol. 24:296-297.

96. Munn, D.H., and Mellor, A.L. 2004. IDO and tolerance to tumors. Trends Mol. Med. 10:15-18.

97. Annacker, O., et al. 2001. CD25+CD4+ T cells regulate the expansion of peripheral CD4 $\mathrm{T}$ cells through the production of IL-10. J. Immunol. 166:3008-3018. 98. Mosmann, T.R., and Coffman, R.L. 1989. TH1 and TH2 cells: different patterns of lymphokine secretion lead to different functional properties. Annu. Rev. Immunol. 7:145-173.

99. Castro, A.G., et al. 2000. Anti-interleukin 10 receptor monoclonal antibody is an adjuvant for $\mathrm{T}$ helper cell type 1 responses to soluble antigen only in the presence of lipopolysaccharide. J. Exp. Med. 192:1529-1534.

100.Thornton, A.M., and Shevach, E.M. 1998. CD4+CD25+ immunoregulatory $\mathrm{T}$ cells suppress polyclonal $\mathrm{T}$ cell activation in vitro by inhibiting interleukin 2 production. J. Exp. Med. 188:287-296.

101.Janeway, C.A., Jr., and Medzhitov, R. 2002. Innate immune recognition. Annu. Rev. Immunol. 20:197-216.

102. Steinman, R.M., Hawiger, D., and Nussenzweig, M.C. 2003. Tolerogenic dendritic cells. Annu. Rev. Immunol. 21:685-711.

103. Goldfeld, A., Doyle, C, and Maniatis, T. 1990. Human tumor necrosis factor alpha gene regulation by virus and lipopolysaccharide. Proc. Natl. Acad. Sci. U. S. A. 87:9769-9773.

104. Goldfeld, A.E., and Maniatis, T. 1989. Coordinate viral induction of tumor necrosis factor alpha and interferon beta in human B cells and monocytes. Proc. Natl. Acad. Sci. U. S. A. 86:1490-1494.

105. Sharpe, A.H. 1995. Analysis of lymphocyte costimulation in vivo using transgenic and 'knockout' mice. Curr. Opin. Immunol. 7:389-395. 